\title{
Refusal: Deciding to Pull the Tube
}

\author{
Jennifer Frank, MD
}

A senior medical student grapples with her patient's end-of-life decisions, which are in stark contrast to the decisions made by her own grandfather facing a similar disease. As she explores her role and responsibility to her patient, she considers what it means to provide futile care and how to negotiate her own beliefs with the demands of her patient's family. (J Am Board Fam Med 2010;23:671-673.)

Keywords: Communication, End-of-Life Care, Ethics

I met Mr. R the first week of my medicine subinternship rotation. In his mid-70s, he was a life-long resident of one of Chicago's close-knit neighborhoods. With disheveled white hair and a tattered navy blue corduroy bathrobe, he sat calmly in the hospital bed as I started my history and physical examination. He clasped his hands loosely in his lap and allowed his eyes to wander around the hospital room. He regarded me briefly before looking for something more interesting to watch.

I started my long list of medical student questions. Do you smoke or have you ever? How old was your mother when she passed away? What did she die from? Are you having any headaches or visual changes?

Most questions prompted a noncommittal yes or no. His severe dementia made his answers suspect. However, I was eager to do the right thing for Mr. R. As a medical student, completing the history and physical seemed to be approximately $99 \%$ of what I had to offer patients. During the course of his admission, I met and spoke with his family members-a wife, whose dementia closely matched his own; a son busy with his own business; an anxious daughter-inlaw; and a handful of nieces, nephews, and grandchildren. They floated in and out of the hospital room without interacting with Mr. R. Although they verbalized their deep concern for his well-being, they seemed to be only peripherally involved in his life.

From the Department of Family Medicine, University of Wisconsin, Appleton.

Funding: none.

Conflict of interest: none declared.

Corresponding author: Jennifer Frank, MD, Department of Family Medicine, University of Wisconsin, 229 S. Morrison St, Appleton, WI 54911 (E-mail: Jennifer.frank@fammed.wisc.edu).
His wife, suffering from end-stage chronic obstructive pulmonary disease in addition to dementia, sat silently in the green vinyl armchair in the corner of the room. I wondered who would help her get home that night.

Mr. R was admitted for complications of metastatic lung cancer. Between his end-stage cancer and his profound dementia, he was failing to thrive at home. His family brought him to the hospital so that we could "fix him up." They were neither interested nor ready for hospice or palliative care. They requested that "everything be done" for him.

I felt particularly close to Mr. R. My own grandfather died of liver cancer just a few months before. As a physician, my grandfather perfectly understood the prognosis when he received his diagnosis. "Okay, then," he said, "I'm going home." He went back to the house he shared with his wife of 50 years, where they raised 3 sons, and started the slow process of leaving this life. A hospice volunteer, he experienced firsthand the benefit and value of hospice care at the end of life and desired that this would be his own treatment plan. He died at home, with an afghan crocheted by my mother around his thin shoulders, as my father said the Lord's Prayer with him. An intensely private man, my grandfather shared the last 3 months of his life only with his wife and sons.

Mr. R's case was clearly terminal, with no hopeful treatments available to him. I searched for reasons why his family would not offer him a peaceful transition like my grandfather experienced, but instead insist that his time be spent in the hospital pursuing remedies that were unlikely to result in any real benefit. With the righteous immaturity of a student doctor who sees only black and white- 
not only in the physiologic aspects of medicine but also in the metaphysical-I attributed many motives to Mr. R's family. Maybe they wanted his Social Security check, I thought. I heard about selfish family members keeping patients alive artificially for weeks or months, such was their greed for the payment their loved one received. Or, I thought, maybe they just don't want to take care of Mrs. R. Mr. and Mrs. R had constructed a delicate balance of living with dementia and chronic illness in a home and neighborhood that offered just enough support so that they could barely get by. If Mr. R died, someone would have to take care of his wife. Finally, I settled into the notion that they must have unresolved issues in their relationship with Mr. R-deep-seated anger or lack of forgiveness that left them unwilling to say goodbye. Then I considered what an unknown medical student might think about my grandfather lying alone on his couch, dying from cancer, with only his wife to hold his hand. Would he wonder where the family was, why grandchildren and daughters-in-law didn't care enough to be there at the end? Likely, he wouldn't see things the way they really were-my grandfather chose a quiet death because he lived a quiet life.

I realize in retrospect that Mr. R's family was like most families who struggle with a terminal prognosis in a loved family member. No dark ulterior motive exists. Only the helpless fear that the doctor might actually be right and there is no cure. The thought that it is too soon and they are not ready for that final hug, kiss, or laugh with someone who is so precious to them.

Because the family wanted "everything" to be done, we did "everything" and more. Tertiary care teaching hospitals excel at doing everything, whether or not it is reasonable. At some point, approximately 10 days into his hospitalization, the family requested that we place a feeding tube because Mr. R was refusing to eat. Having recently completed my geriatrics rotation, I knew a feeding tube was likely to only prolong the poor quality of life that characterizes protracted end-of-life hospitalizations. With the shaky confidence of a senior medical student, I tried to reason with the family members. "This probably won't help him and may just prolong his suffering." The family persisted, unified in belief that this must be done. I expected the surgeons to decline because they must be even more knowledgeable about the futility of this so-called treatment. Not surprisingly, the referral generated the procedure.

Mr. R returned to his room after the feeding tube was placed. It was approximately 6:00 at night and the hospital was settling in for the evening. The dinner trays were being collected, resident sign-out was occurring, and the night shift was arriving as I stopped by to check on my patient.

Mr. R lay strapped down in the hospital bed, heavily sedated. His nurse looked up from the intravenous pump she was programming to tell me that he was pulling at the feeding tube poking out of his abdomen. "We tied his wrists down so he wouldn't pull it out," she explained. I silently apologized to Mr. R for not preventing this from happening and walked defeated to the sign-out room.

I was paged approximately 15 minutes later by the nurse. "He pulled the feeding tube out. What should we do?" As so often happened during this early part of my training, I silently questioned why she was asking me what to do. I knew almost nothing about the practical application of medical knowledge to patient care. I sought out the gastroenterology fellow for advice. "It's not a big deal," he reassured me. "Just drop [a nasogastric] tube to decompress his stomach. We'll put a new feeding tube in tomorrow."

I gathered the necessary supplies and asked the nurse to assist me. I felt increasingly complicit in what was feeling less like futile care and more like assault. I didn't know how to turn back this process and apply a more thoughtful and reasonable approach to Mr. R's care.

Seeking to reassure him and anticipating that he was probably feeling fearful and confused, I explained what I was about to do. "Mr. R," I began. "I need to put this tube in your nose to protect your stomach." I put on my gloves, dipped the end of the tube in surgi-lube and started inserting it into his left nostril as 2 nurses held his arms down.

He struggled, shaking his head back and forth. "Mr. R, this isn't going to hurt. It'll just be a bit uncomfortable. Hold still, please." I was at least telling the truth here. We experienced nasogastric tube placement as part of our physiology class, so I knew what he would be feeling. I tried again and his nose started bleeding. Mr. R looked me right in the eye. It was the only lucid expression I ever saw on his face. "Please," he said in a soft voice. "No. No." Through the drugs and the dementia, through the 
demeaning nature of being old, frail, and ill, Mr. R had spoken: No.

I stopped, tears starting to run down my face, ashamed that a patient had so quickly broken me. "Stop," I told the nurses. "We're not doing this." I wondered what the nurse thought as she watched me, an inexperienced, obviously emotionally distraught medical student. I could no more place that nasogastric tube than I could give him a lethal dose of potassium. I thought of the road my grandfather had chosen, to be at home, far from the hospital that had been his professional residence for decades. Intimately familiar with all that medical technology could provide, he knew when to turn away and embrace the end with grace and humility and in the manner he chose.

Certain in the moral line I would not cross, I inwardly cringed to consider what the gastrointestinal fellow or my attending physician would say when I reported my failure to them. I left Mr. R's room in search of my attending physician, anxious to admit my failing and ready for the verbal punishment I would face for not being up to the medical task that was mine to do.

Finding my attending physician, I confessed, "I can't do this. It's not right. He's my patient, and he said 'no'. If that NG tube is getting placed, it will have to be by someone else."

My attending physician surprised me. He said, "Okay." When he saw the astonishment on my face at his easy acceptance of my decision, he went on to explain. "Look, I take care of a lot of patients who are dying from AIDS. Many have families that have abandoned them or haven't been involved because they used drugs or are gay. At the end, families often step in and try to direct what kind of care I 'have to' provide. They ignore the patient's partner because they don't approve of the relationship. I disregard the family's requests if they go against what the patient would want or if I think it is futile care." Wow, I thought. I didn't know we could be so decisive in what we did or didn't do for our patients.

We discussed a plan of care that merged what the family was requesting, as Mr. R's legal decision makers, with what was ethically and medically reasonable, ultimately electing to decline replacement of the feeding tube on the basis that it was futile care. I stopped by Mr. R's room later that evening. He was sleeping with his head turned slightly to the right. In the dim light of the hospital room, I saw a dried trickle of blood at his left nares. His mouth was opened slightly and he made a "huss, huss" sound as he breathed in and out. As he lay there, peaceful at last, I considered his short future. I hoped the small measure of sparing him a feeding tube and the accompanying chemical and physical restraints that would be needed to keep it in place would buy him some measure of comfort and approximate how I imagined my grandfather's last days to be. I patted his hand, finally unleashed from the nylon hold of the restraint. "Good night, Mr. R." 